\title{
Effects of balance and plyometric training on balance control among individuals with functional ankle instability
}

\author{
DOI: https://doi.org/10.5114/pq.2020.92474
}

\author{
Aileen Surakhamhaeng, Sunee Bovonsunthonchai, Roongtiwa Vachalathiti \\ Faculty of Physical Therapy, Mahidol University, Nakhon Pathom, Thailand
}

\begin{abstract}
Introduction. This study aimed to compare the effects of balance and plyometric training on balance control among individuals with functional ankle instability (FAl).

Methods. Overall, 20 individuals with FAI, classified in balance $(n=10)$ and plyometric $(n=10)$ training groups, participated in the study. Testing variables included standard deviations and ranges of centre of pressure in mediolateral (ML-COPsd/ML$\mathrm{COPr}$ ) and anteroposterior (AP-COPsd/AP-COPr) directions during single-legged stance with eyes open and closed, times to stabilization of ground reaction force in mediolateral (ML-TTS) and anteroposterior (AP-TTS) directions during step-down, and reach distances in anterior, posteromedial, and posterolateral directions from the modified Star Excursion Balance Test.

Results. When comparing between the groups, the plyometric training group exhibited a significant reduction of ML-COPsd with eyes open after 6 weeks of training $(p=0.004)$ and shorter ML-TTS and AP-TTS after 4 weeks $(p=0.009$ and $p=0.007)$ and 6 weeks $(p=0.011$ and $p=0.029)$ of training. For within-group comparison, the plyometric training group showed significant improvements $(p<0.05)$ in all testing variables, whereas the balance training group presented improvement only in the reach distances.
\end{abstract}

Conclusions. Plyometric training provided benefits in both static and dynamic balances for individuals with FAI.

Key words: functional ankle instability, plyometric, balance

\section{Introduction}

Ankle sprains usually occur in several sports and daily activities. They lead to a diminished proprioceptive sense and poor postural control. Individuals with repetitive ankle sprain often experience functional ankle instability (FAI) [1] and symptoms may develop to a chronic stage eventually $[2,3]$. Chronic ankle instability negatively alters the central mechanisms of motor control and leads to a greater risk of falling [4]. After the first ankle sprain, $73-80 \%$ of individuals experience recurrent ankle sprains [5, 6]. This repetitive injury results in joint degeneration and increases the risk of osteoarthritis [7].

Individuals with FAI usually present postural instability during static and dynamic movements. Several laboratory and clinical tools are used to quantify the degree of postural instability [8-12]. With the use of a force plate in measurement, ground reaction force (GRF) and centre of pressure (COP) displacement/velocity are usually applied to distinguish balance control between conditions with and without ankle instability $[11,13]$. In the clinical setting, the Star Excursion Balance Test (SEBT) is used to determine dynamic balance in multiple directions. Good postural control requires an optimal range of motion, flexibility, proprioception, and neuromuscular control of the lower extremities [8]. Higher variations of COP during single-legged stance $[1,13]$ and a longer time to stabilize (TTS) GRF during step-down [13] were reported among individuals with FAI when compared with healthy subjects. In addition, individuals with FAI had a lower reach distance in all testing directions [14].

Balance training is commonly performed by athletes and injured people with FAI $[1,15,16]$. Related studies have re- ported that balance exercise was effective to improve balance control among individuals with chronic ankle instability $[9,16,17]$. In addition, strengthening exercises for the lower extremity and stimulating proprioceptive joint function could also improve postural balance function among individuals with ankle instability $[18,19]$.

Plyometric training is frequently applied in many kinds of sport. Its benefits include stimulating sensory and proprioceptive functions and strengthening the tendons and fast-twitch fibres of the muscle. With a repetitive stretch-shortening cycle of the plyometric training, an efficient neuromuscular function can be gained through good coordinated control between the neural and muscle systems [20, 21]. The training promotes agility, muscular power, rapid force production, stability, and functional performance [20-22]. The reviewed articles have proved it to be a feasible and safe training to improve function and performance among the elderly and children $[23,24]$. However, to prevent potential injury that may occur in nonathletic individuals, it is essential to set a low level of intensity and difficulty at first and to follow the recommended guideline protocols.

Therefore, this study aimed to compare the effects of plyometric and balance training on balance control among individuals with FAl. Owing to the advantages of plyometric training on sensory and proprioceptive stimulation and lower extremity muscles and tendon strengthening, we hypothesized that plyometric training might provide more benefits for improving postural balance than balance training.

Correspondence address: Sunee Bovonsunthonchai, Faculty of Physical Therapy, Mahidol University, 999 Phuttamonthon 4 Rd., Salaya, Phuttamonthon, Nakhon Pathom, 73170, Thailand, e-mail: sunee.bov@mahidol.edu

Received: 26.08 .2019

Accepted: 17.11 .2019

Citation: Surakhamhaeng A, Bovonsunthonchai S, Vachalathiti R. Effects of balance and plyometric training on balance control among individuals with functional ankle instability. Physiother Quart. 2020;28(2):38-45; doi: https://doi.org/10.5114/pq.2020.92474. 
Table 1. Baseline demographic data of the balance and plyometric training groups

\begin{tabular}{|l|c|c|c|}
\hline Variables & $\begin{array}{c}\text { Balance training group } \\
(n \text { or mean } \pm S D)\end{array}$ & $\begin{array}{c}\text { Plyometric training group } \\
(n \text { or mean } \pm S D)\end{array}$ & 10 \\
\hline Number of participants & 10 & $4 / 6$ & $0.639^{\mathrm{a}}$ \\
\hline Sex (male/female) & $3 / 7$ & $6 / 4$ & $1.000^{\mathrm{a}}$ \\
\hline Side of ankle sprain (left/right) & $6 / 4$ & $70.42 \pm 7.62$ & $0.320^{\mathrm{b}}$ \\
\hline Weight $(\mathrm{kg})$ & $65.70 \pm 12.45$ & $169.90 \pm 7.37$ & $0.129^{\mathrm{b}}$ \\
\hline Height $(\mathrm{cm})$ & $165.10 \pm 6.06$ & $27.70 \pm 4.94$ & $0.179^{\mathrm{b}}$ \\
\hline Age $($ years) & $25.10 \pm 3.18$ & $24.54 \pm 3.25$ & $0.852^{\mathrm{b}}$ \\
\hline BMI (kg/m $)$ & $24.24 \pm 3.82$ & $2.40 \pm 1.26$ & $0.339^{\mathrm{b}}$ \\
\hline Number of sprains & $1.90 \pm 0.99$ & $18.50 \pm 11.00$ & $0.903^{\mathrm{b}}$ \\
\hline Onset of the most recent sprain (months) & $19.10 \pm 10.70$ & $17.10 \pm 6.95$ & $0.680^{\mathrm{b}}$ \\
\hline CAIT score & $18.30 \pm 5.81$ & & \\
\hline
\end{tabular}

$\mathrm{BMI}$ - body mass index, CAIT - Cumberland Ankle Instability Test

a significant difference tested by the chi-square test at $p<0.05$

${ }^{\mathrm{b}}$ significant difference tested by the independent sample $t$-test at $p<0.05$

\section{Subjects and methods}

\section{Participants}

The following inclusion criteria were assumed: (1) history of unilateral or bilateral ankle sprain at least one time; to prevent unexpected injury during testing, the less severe side was chosen when subjects had sprained both ankles; (2) the most recent lateral ankle sprain > 6 months; (3) being able to perform one-leg stand with full weight-bearing on the injured side at least 3 weeks before the test; (4) Cumberland Ankle Instability Test (CAIT) score $\leq 27$ of the full score of 30 [25]; (5) age ranging from 18 to 45 years; (6) negative anterior drawer and talar tilt test results; (7) experiencing no pain while walking and jumping vertically. The exclusion criteria involved history of fracture or surgery within the lower extremity, obesity (body mass index $>30 \mathrm{~kg} / \mathrm{m}^{2}$ ), visual analogue scale score for pain $>3 / 10$ at the ankle while participating in the study, and abnormal foot alignment.

A total of 20 individuals with FAl comprising 7 males and 13 females participated in the study. They were randomly allocated to the balance or plyometric training groups by drawing lots from a concealed envelope. Table 1 presents the demographic data of the participants in the balance and plyometric training groups. At baseline, sex, ankle sprain side, weight, height, age, body mass index, number of ankle sprains, onset of the most recent ankle sprain, or CAIT score did not significantly differ between groups $(p>0.05)$.

\section{Testing protocol}

All measures were tested on 3 separate occasions: at baseline, after 4 weeks of training, and after 6 weeks of training. Single-legged stance and step-down test results were collected by using a 3D motion analysis system (Vicon ${ }^{\mathrm{TM}}$, Oxford, UK), comprising 10 high-speed cameras (Vantage series) and a force plate (Advanced Mechanical Technologies Inc., USA). Kinematic and kinetic data were obtained at a frequency of $100 \mathrm{~Hz}$ and $1000 \mathrm{~Hz}$. A set of 16 markers following the lower extremity Plug-In-Gait model was used. The markers were attached to the bilateral anterior-superior iliac spines, posterior-superior iliac spines, lateral thighs, lateral knee joints, lateral shanks, lateral malleoli, posterior heels, and the $2^{\text {nd }}$ metatarsal bones. This visualized PlugIn-Gait model assisted in the GRF events tracking process. Kinetic data were filtered with the fourth-order Butterworth low pass method with cut-off frequencies of $15 \mathrm{~Hz}$ for the single-legged stance and $25 \mathrm{~Hz}$ for the step-down.

\section{Measures}

Standard deviations $(S D)$ of COP $(\mathrm{mm})$ in mediolateral (ML-COPsd) and anteroposterior (AP-COPsd) directions, and ranges of $\mathrm{COP}$ in mediolateral (ML-COPr) and anteroposterior (AP-COPr) directions were collected by using a force plate. The participants stood on their unstable foot or less severe FAl foot on the force plate, arms crossed on the chest, eyes open and looking straightforward or eyes closed while standing still on their single leg for 20 seconds. To obtain reliable results, the participants performed two practice trials before the 3 real testing trials [26].

The TTS (in seconds) of GRF in mediolateral (ML-TTS) and anteroposterior (AP-TTS) directions were collected during the step-down test from a box $30 \mathrm{~cm}$ in height on the force plate. TTS data were analysed following the method used by Colby et al. [27]. The ML-TTS and AP-TTS were determined by sequential estimation. This technique incorporates an algorithm to calculate a cumulative average of the data points in series by successively adding one point at a time. The cumulative average was compared with the overall series mean. Stable series were considered when the sequential average remained within $0.25 S D$ of the overall series mean. The TTS in vertical GRF was established as the time when the vertical force component reached and stayed within $5 \%$ of the subject's body weight after landing. In addition, the markers were used to monitor the subject's movement when they stepped down onto the force plate.

Reach distances of a single leg in the anterior, posteromedial, and posterolateral directions were obtained from the modified SEBT. The participants stood on the unstable leg and used the other leg to move in each direction as far as possible. The absolute reach distance scores $(\mathrm{cm})$ were averaged from 3 trials. Then, normalized reach distance (\%) and composite reach distance scores (\%) were computed with the use of the following formula [28]: 
normalized reach distance $(\%)=$ absolute reach distance / leg length * 100

composite reach distance $(\%)=$ sum of the 3 reach directions / 3 * leg length * 100

\section{Training program}

The balance and plyometric training programs applied in the present study were modified from related studies [21, 29]. Table 2 presents the details of the training programs for the balance and plyometric groups. Both groups were trained for 3 days/week over 6 weeks. The total training time for each session was 20 minutes. To prevent injury and to prepare the participants promptly for the exercises, both groups performed the same warm-up and cool-down. Each week contained 4 types of exercises, and the difficulty level of the exercises progressed over the weeks.

For the balance training program, the exercises performed under both eyes open and closed conditions depended on the training week. The subjects trained on the floor surface in the $1^{\text {st }}$ and $2^{\text {nd }}$ weeks, and on the tilt board in the remaining weeks. The tilt board was adjusted to train for balance in both the anteroposterior and mediolateral directions for 2 sessions each. The participants had to control their balance for $60 \mathrm{sec}-$ onds and took a rest for 60 seconds between exercises. For the plyometric training program, the difficulty was adjusted in accordance with the week by the movement direction, involving the muscles and the number of legs used to support the weight when jumping. Each exercise was performed 15 times/set for 2 sets, with a 60-second rest allowed in between.

\section{Statistical analyses}

All data were analysed with the SPSS software version 22.0 (SPSS Inc., Chicago, USA). The level of difference significance was set at $p<0.05$ for all comparisons. The data demonstrated non-normal distribution, so nonparametric statistics was used in this study. For descriptive data, medians with the first and third quartiles (Q1, Q3) were presented. Friedman two-way ANOVA was used to test differences of the grand mean of the data. For between-group comparisons, the Mann-Whitney U test was applied to test data differences. In addition, a within-subject comparison among time points of assessment was performed by using the Friedman test. When data showed a significant difference, a pairwise comparison with the Bonferroni adjustment technique at $p<0.05 / 3$ or $p<0.017$ was used to determine the difference.

\section{Sample size calculation}

The main problem of individuals with FAl was the instability, especially in the mediolateral direction, caused by repetitive injury of lateral ankle sprain. The sample size was estimated on the basis of our own pilot data ( $n=5$ for each group) on the variables of the ML-COPsd and ML-TTS at the $6^{\text {th }}$ week of training. The $\mathrm{G}^{*} \mathrm{Pow}$ r software, version 3.1.9.2, with the function to compare differences between two independent groups, served to perform the Wilcoxon-Mann-Whitney test and to set the alpha error probability of 0.05 and power of 0.80 . The sample size per each group calculated on the basis of ML-COPsd and ML-TTS equalled 8 and 4, respectively. Hence, the number of participants recruited in the study was probably sufficient to answer the research question.

\section{Ethical approval}

The research related to human use has complied with all the relevant national regulations and institutional policies, has followed the tenets of the Declaration of Helsinki, and has been approved by the authors' institutional research ethics committee (COA No.: MU-CIRB 2016/074.0706).

\section{Informed consent}

Informed consent has been obtained from all individuals included in this study.

Table 2. Training programs for the balance and plyometric groups

\begin{tabular}{|c|c|c|c|c|c|c|}
\hline \multirow{2}{*}{$\begin{array}{l}\text { Warm-up } \\
\text { and cool-down }\end{array}$} & \multicolumn{4}{|c|}{ Balance training program } & \multicolumn{2}{|c|}{ Plyometric training program } \\
\hline & $\begin{array}{l}\text { Phase } \\
\text { (week) }\end{array}$ & Eyes & Surface & Exercise & $\begin{array}{l}\text { Phase } \\
\text { (week) }\end{array}$ & Exercise \\
\hline \multirow{2}{*}{$\begin{array}{l}\text { 1. Warm-up } \\
\text { Side step jack } \\
\text { Jogging } \\
\text { Double knee pulls } \\
\text { Jumping jack }\end{array}$} & $\begin{array}{c}\text { I } \\
\text { (week 1) }\end{array}$ & $\begin{array}{l}\text { Open } \\
\text { Open } \\
\text { Open } \\
\text { Open }\end{array}$ & $\begin{array}{l}\text { Floor } \\
\text { Floor } \\
\text { Floor } \\
\text { Floor }\end{array}$ & $\begin{array}{l}\text { Single-leg stance } \\
\text { Single-leg stance while swinging the raised leg } \\
\text { Single-leg squat }\left(30-45^{\circ}\right) \\
\text { Single-leg stance while performing kicking }\end{array}$ & \multirow{2}{*}{$\begin{array}{c}\text { I } \\
\text { (weeks 1-2) }\end{array}$} & \multirow{2}{*}{$\begin{array}{l}\text { Ankle jump } \\
\text { Ski jump } \\
\text { Skater } \\
\text { Squat jump }\end{array}$} \\
\hline & $\begin{array}{c}\text { II } \\
\text { (week 2) }\end{array}$ & $\begin{array}{l}\text { Closed } \\
\text { Closed } \\
\text { Closed } \\
\text { Closed }\end{array}$ & $\begin{array}{l}\text { Floor } \\
\text { Floor } \\
\text { Floor } \\
\text { Floor }\end{array}$ & $\begin{array}{l}\text { Single-leg stance } \\
\text { Single-leg stance while swinging the raised leg } \\
\text { Single-leg squat }\left(30-45^{\circ}\right) \\
\text { Single-leg stance while performing kicking }\end{array}$ & & \\
\hline \multirow{3}{*}{$\begin{array}{l}\text { 2. Stretching } \\
\text { (cool-down) } \\
\text { Calf stretch } \\
\text { Quadriceps stretch } \\
\text { Hamstring stretch } \\
\text { Inner thigh stretch } \\
\text { Hip flexor stretch }\end{array}$} & $\begin{array}{c}\text { III } \\
\text { (week 3) }\end{array}$ & $\begin{array}{l}\text { Open } \\
\text { Open } \\
\text { Open } \\
\text { Open }\end{array}$ & $\begin{array}{l}\text { Board } \\
\text { Board } \\
\text { Board } \\
\text { Board }\end{array}$ & $\begin{array}{l}\text { Single-leg stance } \\
\text { Single-leg stance while swinging the raised leg } \\
\text { Single-leg squat }\left(30-45^{\circ}\right) \\
\text { Double-leg stance while tilting the board }\end{array}$ & \multirow{2}{*}{$\begin{array}{c}\text { II } \\
\text { (weeks 3-4) }\end{array}$} & \multirow{2}{*}{$\begin{array}{l}\text { Heisman } \\
\text { Low squat foot switch } \\
\text { Two-feet front } \\
\text { to back ankle hop } \\
\text { Two-feet side to side } \\
\text { ankle hop }\end{array}$} \\
\hline & $\begin{array}{c}\text { IV } \\
\text { (week 4) }\end{array}$ & $\begin{array}{l}\text { Closed } \\
\text { Open } \\
\text { Open } \\
\text { Open }\end{array}$ & $\begin{array}{l}\text { Board } \\
\text { Board } \\
\text { Board } \\
\text { Board }\end{array}$ & $\begin{array}{l}\text { Single-leg stance } \\
\text { Single-leg stance while swinging the raised leg } \\
\text { Single-leg squat }\left(30-45^{\circ}\right) \\
\text { Single-leg stance while tilting the board }\end{array}$ & & \\
\hline & $\begin{array}{l}\text { V-VI } \\
(\text { weeks } \\
5-6)\end{array}$ & $\begin{array}{l}\text { Closed } \\
\text { Open } \\
\text { Open } \\
\text { Open }\end{array}$ & $\begin{array}{l}\text { Board } \\
\text { Board } \\
\text { Board } \\
\text { Board }\end{array}$ & $\begin{array}{l}\text { Single-leg stance } \\
\text { Single-leg squat }\left(30-45^{\circ}\right) \\
\text { Single-leg stance while tilting the board } \\
\text { Single-leg stance while performing kicking }\end{array}$ & $\begin{array}{c}\text { III } \\
\text { (weeks 5-6) }\end{array}$ & $\begin{array}{l}\text { Heisman } \\
\text { Low squat in and out } \\
\text { One-leg ankle jump } \\
\text { One-leg side to side } \\
\text { ankle hop }\end{array}$ \\
\hline
\end{tabular}




\section{Results}

Friedman two-way ANOVA revealed significant differences for almost all balance measures. In the eyes-open test, differences were found in ML-COPsd $\left(\chi^{2}=18.171, p=0.003\right)$, AP-COPsd $\left(\chi^{2}=15.259, p=0.009\right), \operatorname{ML}-\operatorname{COPr}\left(\chi^{2}=14.800\right.$, $p=0.011)$, and AP-COPr $\left(\chi^{2}=13.086, p=0.023\right)$. In the eyesclosed test, differences were observed in ML-COPsd $\left(\chi^{2}=\right.$ $15.314, p=0.009)$, AP-COPsd $\left(\chi^{2}=12.364, p=0.030\right)$, $\operatorname{ML}-\operatorname{COPr}\left(\chi^{2}=15.029, p=0.010\right)$, and AP-COPr $\left(\chi^{2}=16.000\right.$, $p=0.007)$. For the step-down test, differences were noted in ML-TTS $\left(\chi^{2}=26.354, p<0.001\right)$ and AP-TTS $\left(\chi^{2}=27.874\right.$, $p<0.001)$. For the reach distances from the modified SEBT, significant differences were detected for the normalized reach distances in the anterior $\left(\chi^{2}=19.200, p=0.002\right)$, posteromedial $\left(\chi^{2}=15.821, p=0.007\right)$, and posterolateral $\left(\chi^{2}=11.379\right.$, $p=0.044)$ directions. In addition, the composite reach distance also showed significant difference $\left(\chi^{2}=20.000, p=0.001\right)$.

Table 3 shows a comparison of balance variables between the two training groups at baseline and after 4 and 6 weeks of training. No significant difference $(p>0.05)$ was found for any balance variable between the groups at baseline. After training, similar results were observed in almost all balance variables between the two groups. A significant difference was revealed for ML-COPsd in single-legged stance with eyes open $(p=0.004)$. The plyometric training group demonstrated a smaller ML-COPsd value when compared with the balance training group after 6 weeks of training. For the stepdown test, the plyometric training group presented a significantly shorter ML-TTS and AP-TTS than the balance training group after 4 weeks $(p=0.009, p=0.007)$ and after 6 weeks of training ( $p=0.011, p=0.029)$.

Table 4 illustrates a comparison of balance variables within the balance and the plyometric training groups among the time points of baseline and after 4 and 6 weeks of training. For the balance training group, significant differences were observed concerning normalized reach distances in the anterior $(p<0.001)$, posteromedial $(p<0.001)$, and posterolateral $(p=$ $0.002)$ directions and in the composite score $(p<0.001)$. With regard to the pairwise comparison with the Bonferroni adjustment test, significant differences were found for reach distances in the anterior direction between baseline and the $4^{\text {th }}$ week of training $(p=0.007)$ and between baseline and the $6^{\text {th }}$ week of training $(p<0.001)$. Significant differences were revealed between baseline and the $6^{\text {th }}$ week of training for the reach distances in the posteromedial $(p<0.001)$, posterolateral $(p=0.001)$, and composite $(p<0.001)$ scores. In the plyometric training group, significant differences $(p<0.05)$ were noted in all balance variables. The pairwise comparisons demonstrated significant differences $(p<0.017)$ between baseline and the $6^{\text {th }}$ week of training among all variables. In addition, significant differences were observed between the $4^{\text {th }}$ and the $6^{\text {th }}$ week of training in the ML-TTS $(p=0.014)$ and AP-TTS $(p=0.014)$ values.

Table 3. Comparison of balance variables between balance and plyometric training groups at each time point of assessment

\begin{tabular}{|c|c|c|c|c|c|c|c|c|c|}
\hline \multirow[b]{2}{*}{ Variables } & \multicolumn{2}{|c|}{ Baseline } & \multicolumn{2}{|c|}{ After 4 weeks of training } & \multicolumn{2}{|c|}{ After 6 weeks of training } & \multirow[b]{2}{*}{$p^{\mathrm{a}}$} & \multirow[b]{2}{*}{$p^{\mathrm{b}}$} & \multirow[b]{2}{*}{$p^{c}$} \\
\hline & $\begin{array}{l}\text { Balance group } \\
\text { Median (IQR) }\end{array}$ & $\begin{array}{l}\text { Plyometric group } \\
\text { Median (IQR) }\end{array}$ & $\begin{array}{l}\text { Balance group } \\
\text { Median (IQR) }\end{array}$ & $\begin{array}{l}\text { Plyometric group } \\
\text { Median (IQR) }\end{array}$ & $\begin{array}{l}\text { Balance group } \\
\text { Median (IQR) }\end{array}$ & $\begin{array}{l}\text { Plyometric group } \\
\text { Median (IQR) }\end{array}$ & & & \\
\hline \multicolumn{10}{|l|}{ Eyes open } \\
\hline ML-COPsd & $6.58(5.15-8.03)$ & $6.98(5.92-9.50)$ & $6.15(5.44-6.66)$ & $6.02(5.14-7.26)$ & $6.27(6.04-7.32)$ & $4.84(4.56-5.57)$ & 0.579 & 0.971 & $0.004^{*}$ \\
\hline AP-COPsd & $6.69(5.71-8.23)$ & $6.24(5.35-8.49)$ & $5.38(4.44-8.11)$ & $5.74(4.68-6.38)$ & $5.71(4.50-6.91)$ & $5.46(4.62-5.79)$ & 0.579 & 0.853 & 0.436 \\
\hline ML-COPr & $26.58(23.13-37.49)$ & $31.09(27.40-39.48)$ & $27.89(24.56-30.02)$ & $26.60(23.77-34.12)$ & $26.82(22.76-29.62)$ & $22.26(20.46-25.24)$ & 0.315 & 0.971 & 0.075 \\
\hline $\mathrm{AP}-\mathrm{COPr}$ & $32.39(26.44-36.81)$ & $28.27(24.30-34.74)$ & $23.20(20.89-37.07)$ & $25.81(23.11-31.49)$ & $28.04(20.34-34.69)$ & 24.40 (21.59-28.88) & 0.529 & 0.796 & 0.353 \\
\hline \multicolumn{10}{|l|}{ Eyes closed } \\
\hline ML-COPsd & $10.97(8.14-13.34)$ & $12.61(10.33-16.30)$ & $10.99(8.61-13.82)$ & $10.07(8.64-15.17)$ & $10.38(7.58-11.49)$ & $8.21(7.29-10.02)$ & 0.280 & 0.912 & 0.353 \\
\hline AP-COPsd & $10.74(10.06-23.36)$ & $10.19(9.07-13.82)$ & $10.31(8.37-20.95)$ & $9.40(8.54-10.94)$ & $11.09(8.02-14.10)$ & $8.26(7.76-9.26)$ & 0.436 & 0.529 & 0.143 \\
\hline $\mathrm{AP}-\mathrm{COPr}$ & $43.72(39.79-76.46)$ & $53.24(39.07-75.10)$ & 46.19 (36.34-74.59) & $48.03(35.41-53.27)$ & $44.77(34.61-65.19)$ & $34.39(31.50-49.51)$ & 0.739 & 0.579 & 0.247 \\
\hline \multicolumn{10}{|l|}{ Step-down } \\
\hline ML-TTS & $2.36(1.34-2.55)$ & $1.85(1.48-2.06)$ & $1.85(1.21-3.09)$ & $1.11(0.87-1.58)$ & $2.01(1.32-2.42)$ & $1.25(0.80-1.46)$ & 0.218 & $0.009^{*}$ & $0.011^{*}$ \\
\hline AP-TTS & $1.64(1.24-2.23)$ & $1.24(1.05-1.81)$ & $1.64(1.14-3.05)$ & $1.04(0.70-1.35)$ & $1.58(1.22-2.29)$ & $0.92(0.54-1.36)$ & 0.315 & $0.007^{\star}$ & $0.029^{*}$ \\
\hline \multicolumn{10}{|c|}{ Normalized reach distance } \\
\hline Anterior & $63.06(56.61-70.73)$ & $63.38(59.33-68.80)$ & 73.35 (66.34-77.68) & $68.85(62.22-71.56)$ & $76.30(68.37-77.67)$ & $71.06(65.96-74.73)$ & 0.821 & 0.199 & 0.199 \\
\hline Posteromedial & $73.77(64.50-89.08)$ & $76.74(67.25-99.00)$ & 88.34 (74.59-94.58) & $90.67(67.96-106.47)$ & $99.82(81.78-102.07)$ & $92.01(72.98-105.16)$ & 0.406 & 0.545 & 0.821 \\
\hline Posterolateral & $83.22(76.30-104.0)$ & 92.08 (81.99-100.07) & $94.33(88.84-100.53)$ & $100.41(83.27-111.26)$ & $100.77(90.69-110.15)$ & $95.47(88.20-116.24)$ & 0.597 & 0.650 & 0.880 \\
\hline $\begin{array}{l}\text { Composite } \\
\text { reach distance }\end{array}$ & $72.73(65.81-88.04)$ & 76.93 (68.94-89.48) & 84.14 (75.91-91.48) & 84.59 (72.62-97.55) & $91.65(80.69-96.07)$ & 85.87 (74.87-98.12) & 0.496 & 0.880 & 0.650 \\
\hline
\end{tabular}

IQR - interquartile range, $\mathrm{ML}$ - mediolateral, $\mathrm{AP}$ - anteroposterior, COP - centre of pressure, sd - standard deviation, $r$ - range,

TTS - time to stabilization

a comparison at baseline

${ }^{\mathrm{b}}$ comparison after 4 weeks of training

${ }^{\mathrm{c}}$ comparison after 6 weeks of training

* significant difference tested by the Mann-Whitney $\mathrm{U}$ test at $p<0.05$ 
Table 4. Comparison of balance variables within balance and plyometric training groups at each time point of assessment

\begin{tabular}{|c|c|c|c|c|c|c|c|c|c|}
\hline \multirow{3}{*}{ Variables } & \multicolumn{4}{|c|}{ Balance training group } & \multirow{3}{*}{ Variables } & \multicolumn{4}{|c|}{ Plyometric training group } \\
\hline & \multirow[b]{2}{*}{$\begin{array}{l}\text { Friedman } \\
\text { test } p^{\mathrm{a}}\end{array}$} & \multicolumn{3}{|c|}{ Pairwise comparison $p^{b}$} & & \multirow[b]{2}{*}{$\begin{array}{l}\text { Friedman } \\
\text { test } p^{\text {a }}\end{array}$} & \multicolumn{3}{|c|}{ Pairwise comparison $p^{b}$} \\
\hline & & $\begin{array}{l}\text { Baseline } \\
\text { vs. after } \\
4 \text { weeks }\end{array}$ & $\begin{array}{l}\text { Baseline } \\
\text { vs. after } \\
6 \text { weeks }\end{array}$ & $\begin{array}{c}\text { After } 4 \text { weeks } \\
\text { vs. after } \\
6 \text { weeks }\end{array}$ & & & $\begin{array}{l}\text { Baseline } \\
\text { vs. after } \\
4 \text { weeks }\end{array}$ & $\begin{array}{l}\text { Baseline } \\
\text { vs. after } \\
6 \text { weeks }\end{array}$ & $\begin{array}{c}\text { After } 4 \text { weeks } \\
\text { vs. after } \\
6 \text { weeks }\end{array}$ \\
\hline \multicolumn{5}{|l|}{ Eyes open } & \multicolumn{5}{|c|}{ Eyes open } \\
\hline ML-COPsd & 0.497 & NA & NA & NA & ML-COPsd & $<0.001^{*}$ & 0.025 & $<0.001^{*}$ & 0.025 \\
\hline AP-COPsd & 0.146 & NA & NA & NA & AP-COPsd & $<0.001^{*}$ & 0.025 & $<0.001^{*}$ & 0.025 \\
\hline ML-COPr & 0.905 & NA & NA & NA & ML-COPr & $<0.001^{*}$ & 0.025 & $<0.001^{*}$ & 0.025 \\
\hline AP-COPr & 0.497 & NA & NA & NA & $\mathrm{AP}-\mathrm{COPr}$ & $0.002^{*}$ & 0.074 & $<0.001^{*}$ & 0.074 \\
\hline \multicolumn{5}{|l|}{ Eyes closed } & \multicolumn{5}{|c|}{ Eyes closed } \\
\hline ML-COPsd & 0.741 & NA & NA & NA & ML-COPsd & $<0.001^{*}$ & 0.025 & $<0.001^{*}$ & 0.025 \\
\hline AP-COPsd & 0.497 & NA & NA & NA & AP-COPsd & $<0.001^{*}$ & 0.025 & $<0.001^{*}$ & 0.025 \\
\hline ML-COPr & 0.082 & NA & NA & NA & ML-COPr & $<0.001^{*}$ & 0.025 & $<0.001^{*}$ & 0.025 \\
\hline $\mathrm{AP}-\mathrm{COPr}$ & 0.497 & NA & NA & NA & $\mathrm{AP}-\mathrm{COPr}$ & $<0.001^{*}$ & 0.025 & $<0.001^{*}$ & 0.025 \\
\hline \multicolumn{5}{|l|}{ Step-down } & \multicolumn{5}{|c|}{ Step-down } \\
\hline ML-TTS & 0.794 & NA & NA & NA & ML-TTS & $0.001^{*}$ & 0.264 & $<0.001^{*}$ & $0.014^{*}$ \\
\hline AP-TTS & 0.836 & NA & NA & NA & AP-TTS & $0.001^{*}$ & 0.264 & $<0.001^{*}$ & $0.014^{*}$ \\
\hline \multicolumn{5}{|c|}{ Normalized reach distance } & \multicolumn{5}{|c|}{ Normalized reach distance } \\
\hline Anterior & $<0.001^{*}$ & $0.007^{*}$ & $<0.001^{*}$ & 0.180 & Anterior & $0.003^{*}$ & 0.044 & $0.001^{*}$ & 0.180 \\
\hline Posteromedial & $<0.001^{*}$ & 0.057 & $<0.001^{*}$ & 0.025 & $\begin{array}{l}\text { Postero- } \\
\text { medial }\end{array}$ & $0.005^{*}$ & 0.019 & $0.003^{*}$ & 0.502 \\
\hline Posterolateral & $0.002^{*}$ & 0.219 & $0.001^{*}$ & 0.025 & $\begin{array}{l}\text { Postero- } \\
\text { lateral }\end{array}$ & $0.013^{*}$ & 0.146 & $0.004^{*}$ & 0.146 \\
\hline $\begin{array}{l}\text { Composite } \\
\text { reach distance }\end{array}$ & $<0.001^{*}$ & 0.025 & $<0.001^{*}$ & 0.025 & $\begin{array}{l}\text { Composite } \\
\text { reach } \\
\text { distance }\end{array}$ & $0.003^{*}$ & 0.044 & $0.001^{*}$ & 0.180 \\
\hline
\end{tabular}

$\mathrm{ML}$ - mediolateral, AP - anteroposterior, COP - centre of pressure, sd - standard deviation, $r$ - range, TTS - time to stabilization,

$\mathrm{NA}$ - not assessed

a significant difference tested by the Friedman test at $p<0.05$

${ }^{\mathrm{b}}$ significant difference tested by pairwise comparison with the Bonferroni adjustment at $p<0.017$

* $p$ values demonstrating a statistically significant difference following the analysis

\section{Discussion}

\section{Comparison of balance variables between the training groups}

Similar to the results obtained among athletes trained with integrated plyometric exercises [1], the plyometric training group demonstrated significantly lower ML-COPsd during the single-legged stance with eyes open after 6 weeks of training. Although the biomechanical study showed greater body sways in both anteroposterior and mediolateral directions in the unstable ankle when compared with the stable ankle [10], the sway was improved in the mediolateral direction only for this study. Improved static balance after the training revealed only in the mediolateral direction may be related to the injuries or sprains of the structures around the ankle, especially the lateral or medial components. In addition, most plyometric exercises in our program focused on jumping forth-back in sideways; thus, balance control in this direction was developed prominently. However, the balance namic balance control more than the static balance control in both anteroposterior and mediolateral directions. Even though this study did not examine the effect of exercises on muscle strength, lower ML-COPsd might have resulted from the stronger muscle contractions obtained after the plyometric training. Related studies have stated that plyometric training could stimulate muscles to perform better co-contraction around the ankle joint [30]. However, no significant difference was found in the single-legged stance with eyes closed in this study. The results were unlike the findings of one related study among athletes that showed significantly improved ML-COPsd during single-legged stance with eyes closed after training with integrated plyometric exercises [1]. This might have occurred because when vision was unavailable, balance control relied mainly on vestibular and somatosensory systems [10]. Improved function during the absence of visual input was difficult [9] and may require more training time to gain the ability in the general population than among athletes with FAl.

Regarding the step-down test, this study found that the plyometric group had shorter ML-TTS and AP-TTS values 
when compared with the balance group after training for 4 and 6 weeks. The similar tasks practised in the plyometric program may explain the gaining of significant improvement of these variables from the step-down test. For instance, during the step-down test, individuals had to step down from an elevated box and land on the force plate placed in front. Therefore, this action was similar to the two-feet front and back ankle hop, ankle jump, and one-leg ankle jump in the plyometric exercise program. In addition, both step-down test and plyometric exercises require individuals to maintain their balance through these transitional dynamic-static states [11], eventually leading to increased ankle stability.

\section{Comparisons of balance variables within the balance training group}

Balance training could improve the dynamics of balance as demonstrated by the improved reach distances in the anterior, posteromedial, and posterolateral directions after 4 and 6 weeks of training, whereas the other variables remained unchanged. This may have resulted from the fact that most exercises in the balance training program emphasized the dynamic movement rather than the static. Each phase of the balance program in this study consisted of four exercises, one focused on static balance and three focused on dynamic balance. During training, the participants had to stabilize their sprained ankles while the other leg performed dynamic movements, such as swinging or kicking. These training exercises were similar to the SEBT movement. During the test, individuals with FAI had to stabilize their sprained ankles while reaching the other leg in several directions as far as possible. Consistent with one related study, the balance training group gained more neuromuscular control, resulting in increased reach distances over different directions [17].

In addition, no significant change was found regarding ankle stability as verified by the step-down test. The stepdown test is a challenging procedure for individuals with FAI $[13,18]$. It measures ankle stability by forcing the subjects to regain balance as fast as possible after stepping down from a $30-\mathrm{cm}$ high box to the force plate. Performing the stepdown test properly required sufficient interaction from the sensorimotor system, ankle muscle strength, and appropriate muscular reaction times [18]. In contrast, the study by Huang et al. [1] found a shorter TTS after training among athletes with FAl. This may have been because the training program used in the study combined the effect of balance and plyometric training and the tested population consisted of athletes.

\section{Comparison of balance variables within the plyometric training group}

After the 6-week training, the plyometric training group showed improved ML-COPsd, ML-COPr, AP-COPsd, and AP-COPr during the single-legged stance under both eyes closed and open conditions. The development of static balance control in both anteroposterior and mediolateral directions may be influenced by the plyometric training program, which assumed jumping and moving in multiple directions.

Postural balance is an important component of the motor system in performing daily activities. Information from the vestibular, visual, and somatosensory systems is integrated to generate a proper postural adjustment. The aim of the postural control system during the upright standing position is to counteract the gravity and inertial force acting on the body segment and maintain the body in the base of support to avoid falling. COP is usually interpreted as the neuromuscular response of the body to maintain balance. It can be monitored by the concepts of position- or velocity-based control [31]. With plyometric exercise training, the afferent information (visual, vestibular, and somatosensory systems), efferent response (muscle contractions and reflexes), and feed-forward and feedback neuromuscular control can be gained [32]. In addition, this may be explained by the improved muscletendon units. It exhibits a greater power through several methods such as stretch reflex, potentiation of the contractile element, use of the elastic energy, and muscle-tendon interaction [15, 20, 33].

For the step-down test, the plyometric training group demonstrated shorter ML-TTS and AP-TTS values, consistent with those reported by Huang et al. [1]. When considering the movement of the plyometric exercises, similar components were involved as with the movement in the stepdown test. Therefore, the participants had to stabilize their balance after perturbation during the exercises. To stabilize the ankle quickly after the step-down test, not only is good muscle strength needed but also the well-firing patterns of neuromuscular control are required [1].

In addition, increased reach distances of the modified SEBT in the anterior, posteromedial, and posterolateral directions were found after the training. One study stated that SEBT was a good tool to detect improved neuromuscular system after training among individuals with unstable ankles [34]. In addition, it indicated the flexibility of the posterior leg muscles. Further, longer reach distances also related to improved stability and balance control. This test constituted a closed kinematic chain motion that needed the muscles around the ankle to work concentric and eccentric contractions alternately. Hence, it could be concluded that the plyometric training enhanced multiple components of the dynamic balance control, which included both concentric and eccentric muscle contractions.

\section{Limitations}

The study may have been limited by a long-term effect of training that was not evaluated. Additionally, the functional assessment conducted in the study should also monitor other factors, such as injury recurrence, pain, and quality of life, which are also important for this population. Furthermore, other types of exercises should be investigated in future studies for proper selection concerning various circumstances.

\section{Conclusions}

The study proved that plyometric training was an effective program for enhancing static and dynamic balance and increasing ankle joint stability among individuals with FAI. Therapists can apply plyometric training in FAI patients to improve their balance control.

\section{Acknowledgements}

This study was partially supported by the Faculty of Graduate Studies, Mahidol University, and the research equipment was provided by Faculty of Physical Therapy, Mahidol University. The authors would like to thank all individuals with FAI who participated in the study and all staff who assisted in the study.

\section{Disclosure statement}

No author has any financial interest or received any financial benefit from this research. 


\section{Conflict of interest}

The authors state no conflict of interest.

\section{References}

1. Huang PY, Chen WL, Lin CF, Lee HJ. Lower extremity biomechanics in athletes with ankle instability after a 6-week integrated training program. J Athl Train. 2014; 49(2):163-172; doi: 10.4085/1062-6050-49.2.10.

2. Hiller CE, Kilbreath SL, Refshauge KM. Chronic ankle instability: evolution of the model. J Athl Train. 2011;46(2): 133-141; doi: 10.4085/1062-6050-46.2.133.

3. Wikstrom EA, Naik S, Lodha N, Cauraugh JH. Balance capabilities after lateral ankle trauma and intervention: a meta-analysis. Med Sci Sports Exerc. 2009;41(6): 1287-1295; doi: 10.1249/MSS.0b013e318196cbc6.

4. Doherty C, Delahunt E, Caulfield B, Hertel J, Ryan J, Bleakley $C$. The incidence and prevalence of ankle sprain injury: a systematic review and meta-analysis of prospective epidemiological studies. Sports Med. 2014;44(1): 123-140; doi: 10.1007/s40279-013-0102-5.

5. Powers ME, Buckley BD, Kaminski TW, Hubbard TJ, Ortiz C. Six weeks of strength and proprioception training does not affect muscle fatigue and static balance in functional ankle instability. J Sport Rehabil. 2004;13(3): 201-227; doi: 10.1123/jsr.13.3.201.

6. Yeung MS, Chan KM, So CH, Yuan WY. An epidemiological survey on ankle sprain. Br J Sports Med. 1994; 28(2):112-116; doi: 10.1136/bjsm.28.2.112.

7. Hertel J. Functional anatomy, pathomechanics, and pathophysiology of lateral ankle instability. J Athl Train. 2002;37(4):364-375.

8. Olmsted LC, Carcia CR, Hertel J, Shultz SJ. Efficacy of the Star Excursion Balance Tests in detecting reach deficits in subjects with chronic ankle instability. J Athl Train. 2002;37(4):501-506.

9. Mettler A, Chinn L, Saliba SA, McKeon PO, Hertel J. Balance training and center-of-pressure location in participants with chronic ankle instability. J Athl Train. 2015; 50(4):343-349; doi: 10.4085/1062-6050-49.3.94.

10. Mitchell A, Dyson R, Hale T, Abraham C. Biomechanics of ankle instability. Part 2: Postural sway-reaction time relationship. Med Sci Sports Exerc. 2008;40(8):15221528; doi: 10.1249/MSS.0b013e31817356d6.

11. Wikstrom EA, Tillman MD, Borsa PA. Detection of dynamic stability deficits in subjects with functional ankle instability. Med Sci Sports Exerc. 2005;37(2):169-175; doi: 10.1249/01.mss.0000149887.84238.6c.

12. Grassi A, Alexiou K, Amendola A, Moorman CT, Samuelsson K, Ayeni OR, et al. Postural stability deficit could predict ankle sprains: a systematic review. Knee Surg Sports Traumatol Arthrosc. 2018;26(10):3140-3155; doi: 10.1007/s00167-017-4818-x.

13. Ross SE, Guskiewicz KM, Gross MT, Yu B. Balance measures for discriminating between functionally unstable and stable ankles. Med Sci Sports Exerc. 2009; 41(2):399-407; doi:10.1249/MSS.0b013e3181872d89.

14. Hertel J, Braham RA, Hale SA, Olmsted-Kramer LC. Simplifying the star excursion balance test: analyses of subjects with and without chronic ankle instability. J Orthop Sports Phys Ther. 2006;36(3):131-137; doi: 10.2519/jospt.2006.36.3.131.

15. Kubo K, Morimoto M, Komuro T, Yata H, Tsunoda N, Kanehisa $\mathrm{H}$, et al. Effects of plyometric and weight training on muscle-tendon complex and jump performance. Med Sci Sports Exerc. 2007;39(10):1801-1810; doi:
16. Rozzi SL, Lephart SM, Sterner R, Kuligowski L. Balance training for persons with functionally unstable ankles. J Orthop Sports Phys Ther. 1999;29(8):478-486; doi: 10.2519/jospt.1999.29.8.478.

17. McKeon PO, Ingersoll CD, Kerrigan DC, Saliba E, Bennett $\mathrm{BC}$, Hertel J. Balance training improves function and postural control in those with chronic ankle instability. Med Sci Sports Exerc. 2008;40(10):1810-1819; doi: 10.1249/MSS.0b013e31817e0f92.

18. Brown CN, Mynark R. Balance deficits in recreational athletes with chronic ankle instability. J Athl Train. 2007; 42(3):367-373.

19. Smith BI, Curtis D, Docherty CL. Effects of hip strengthening on neuromuscular control, hip strength, and selfreported functional deficits in individuals with chronic ankle instability. J Sport Rehabil. 2018;27(4):364-370; doi: 10.1123/jsr.2016-0143.

20. Chimera NJ, Swanik KA, Swanik CB, Straub SJ. Effects of plyometric training on muscle-activation strategies and performance in female athletes. J Athl Train. 2004; 39(1):24-31.

21. Myer GD, Ford KR, McLean SG, Hewett TE. The effects of plyometric versus dynamic stabilization and balance training on lower extremity biomechanics. Am J Sports Med. 2006;34(3):445-455; doi: 10.1177/036354650528 1241.

22. Oxfeldt M, Overgaard K, Hvid LG, Dalgas U. Effects of plyometric training on jumping, sprint performance, and lower body muscle strength in healthy adults: a systematic review and meta-analyses. Scand J Med Sci Sports. 2019;29(10):1453-1465; doi: 10.1111/sms.13487.

23. Vetrovsky T, Steffl M, Stastny P, Tufano JJ. The efficacy and safety of lower-limb plyometric training in older adults: a systematic review. Sports Med. 2019;49(1): 113-131; doi: 10.1007/s40279-018-1018-x.

24. Johnson BA, Salzberg CL, Stevenson DA. A systematic review: plyometric training programs for young children. J Strength Cond Res. 2011;25(9):2623-2633; doi: 10.1519/JSC.0b013e318204caa0.

25. Hiller CE, Refshauge KM, Bundy AC, Herbert RD, Kilbreath SL. The Cumberland ankle instability tool: a report of validity and reliability testing. Arch Phys Med Rehabil. 2006;87(9):1235-1241; doi: 10.1016/j.apmr.2006.05.022.

26. Wang HK, Chen $\mathrm{CH}$, Shiang TY, Jan MH, Lin KH. Riskfactor analysis of high school basketball-player ankle injuries: a prospective controlled cohort study evaluating postural sway, ankle strength, and flexibility. Arch Phys Med Rehabil. 2006;87(6):821-825; doi: 10.1016/j. apmr.2006.02.024.

27. Colby SM, Hintermeister RA, Torry MR, Steadman JR. Lower limb stability with ACL impairment. J Orthop Sports Phys Ther. 1999;29(8):444-451; discussion 452-454; doi: 10.2519/jospt.1999.29.8.444.

28. Shaffer SW, Teyhen DS, Lorenson CL, Warren RL, Koreerat $\mathrm{CM}$, Straseske CA, et al. Y-balance test: a reliability study involving multiple raters. Mil Med. 2013;178(11): 1264-1270; doi: 10.7205/MILMED-D-13-00222.

29. Myer GD, Ford KR, Brent JL, Hewett TE. The effects of plyometric vs. dynamic stabilization and balance training on power, balance, and landing force in female athletes. J Strength Cond Res. 2006;20(2):345-353; doi: 10.1519/ R-17955.1.

30. Kenney WL, Wilmore JH, Costill DL. Physiology of sport and exercise, $6^{\text {th }}$ ed. Champaign: Human Kinetics; 2015.

31. Portela FM, Rodrigues EC, de Sá Ferreira A. A critical review of position- and velocity-based concepts of pos- 
tural control during upright stance. Hum Mov. 2014; 15(4):227-233; doi: 10.1515/humo-2015-0016.

32. Lephart SM, Abt JP, Ferris CM, Sell TC, Nagai T, Myers JB, et al. Neuromuscular and biomechanical characteristic changes in high school athletes: a plyometric versus basic resistance program. Br J Sports Med. 2005;39(12):932938; doi: 10.1136/bjsm.2005.019083.

33. Hirayama K, Iwanuma S, Ikeda N, Yoshikawa A, Ema R, Kawakami Y. Plyometric training favors optimizing muscletendon behavior during depth jumping. Front Physiol. 2017;8:16; doi: 10.3389/fphys.2017.00016.

34. Hale SA, Hertel J, Olmsted-Kramer LC. The effect of a 4-week comprehensive rehabilitation program on postural control and lower extremity function in individuals with chronic ankle instability. J Orthop Sports Phys Ther. 2007;37(6):303-311; doi: 10.2519/jospt.2007.2322. 